\title{
Estimating the Cost of Operating Theater Services at Assuit University Hospital
}

\author{
Eman Mohamed Elshazly, Kawther Abd-EL-Motagaly Fadel, Samah Mohamed Abdalla \& Fatma Rushdy \\ Mohamed.
}

Assistant lecturer of Nursing Administration, Faculty of Nursing, South Valley University, Qena, Egypt.

Professor of Public Health and Community Medicine, Faculty of Medicine, Assuit University, Assuit, Egypt.

Professor of Nursing Administration, Faculty of Nursing, Assuit University, Assiut, Egypt.

Assistant Professor of Nursing Administration, Faculty of Nursing, Assuit University, Assiut, Egypt.

\begin{abstract}
The increasing healthcare costs have forced the healthcare managers to know the cost of different alternatives approaches to providing care. This study aims to estimate the costs of general surgical operating theater services at Assuit University Hospital. Subject\& Methods: Subjects of the study included three types :-( patient's records, surgeons, and nurses).The total subjects of this study (Total number=280 patients records), the records of this study scheduled for surgery as follows: Major, Minor, and Technically Advanced Operations. Data collection: was done by using: Retrospective Review Tool of operations Performed in Year (2011) , Monitoring Form for Operating Theater" to record activities performed by nursing staff and auxiliary; and Costing and Pricing List Form for Surgical Procedures in Operating theater. Results: direct (variable, fixed) costs and indirect costs were higher for major and technically advanced operations than minor operations. The minor, major operations done under spinal anesthesia were less in their total basic direct variable cost. indirect costs for all surgeries, anesthesia, nursing and operating theaters represents the highest costs among the (indirect costs) for technically advanced operations than in major and minor operations. Recommendations: Increase awareness of nurses about the importance of calculates the cost to maintain cost reduction. Proper utilization of operating theater time by using an organized surgeries list and coordinating activities between the surgical departments and operating theater to reduce the surgery's waiting time. In-service training programs for newly employed nursing personnel about operating theater services.
\end{abstract}

\section{Keywords: Direct variable costs, Direct fixed costs, indirect costs, Nurses \& Operations.}

\section{Introduction}

The backbone of any hospital is its ability to maintain financial solvency. Nurses have a significant role in making this happen .As the largest group of health care providers in any organization, nurses has an obligation to assist in the growth and financial stability of the organization (Klainberg \& Dirschel, 2010).

As health care becomes increasingly competitive, the priority of hospital is turned to provide the highest quality of healthcare at the lowest possible cost. Hospitals are constantly seeking ways to control cost and effectively use scare resources. Recent trends in healthcare reform require nurse managers to manage diminishing resources efficiently. Because political, as well as competitive pressures, have resulted in a reduction of the growth of revenues, cost control is extremely important to the viability of the healthcare Organization (Kaiser, 2009).

Consequently, the initial challenge for nursing administrators is to identify the critical processes of the hospital, and one of the hospital's core processes involves the procedures of the operating theater (OT) which is classified as the most critical resources that generate highest costs for a hospital (Dall, Chen, \& Seifert, 2009).
The operating theater costs form the largest percentage of expenditure its huge portion of the money spent on the surgical services, where a significant amount of resources in a hospital are dedicated to operating theaters as these play an integral role in hospitals which deliver surgical care (Bank of Valletta Review, 2007).

Focusing on (OT) processes proved to be one important level for improving the overall quality of hospital services. An (OT) budget may comprise $10 \%$ to $15 \%$ of a hospital's total annual operating budget. In the French context of healthcare expenses control, the operating theater represents $9 \%$ of hospital's annual budget. A recent report predicted an increase in demand for surgical services to be as high as $14 \%$ to $47 \%$ in the workload of all surgical fields (Lemke, Ratib, \& Hori, 2005).

Operational operating theater management focuses on maximizing operational efficiency at the facility. To maximize the number of surgical cases that can be done on a given day while minimizing the required resources and related costs (Dexter et al., 2007). In order to measure the cost of the surgical procedure, many hospitals have developed their own operations classification systems. A classification system for 
operations and surgical procedures that used by a variety of Egyptian hospitals are Minor, Major and Technically Advanced Operations (Dier and Bozzo, 1997).

\section{Significance of the Study}

Today, the cost of operating theater is huge due to advances in technology, complexity of medical care and resources. Aiming to improve quality and cost efficiency of its services without reducing the quality of patient care which resulting in more patient satisfaction, cutting for unnecessary services. Therefore, it was necessary to estimate costs of operating theater services.

\section{Aim of the Study}

To estimate the cost of general surgical operating theater services at Assuit University Hospital?

\section{Research Questions}

- What is the cost of minor, major and technical advanced operations?

- What is the cost of supplies used in minor, major and technical advanced operations?

\section{Subjects and Methods}

\section{Technical design:}

This design included the study design, setting, Subjects, and Data Collection Tools.

\section{Study Design}

The design of the study is a descriptive design.

\section{Setting}

The present study was conducted in the general surgical operating theater located in Assiut University Hospital.The rate of patient's admissions 2800 yearly for different classification of operations. Operating theater is consisting of five operating theaters first and second rooms for major operations, the third and fourth for minor Operations, and fifth for technically advanced operations. The general surgical department includes (154) beds distributed on two floors in the hospital.

\section{Subjects}

The present study included 280 patients record. The total subjects of this study comprised of each type of surgery representing $10 \%$ of the total patient admitted for the operating theaters. This estimation of total sample of the present study was based on reviewing the number of operations done in general surgical operating theater in the year 2011 (total number $=2800$ patients record), the records of this study scheduled for surgery as follows:

- Major Operations.

- Minor Operation.

- Technically Advanced Operations.
- All surgeons staff categories $(\mathrm{N}=60)$ distributed as follows: professor surgeon (11), assistant professor (3), lecturer (6), assistant lecturer (8), and residence (32).

- All nursing staff and auxiliaries $(\mathrm{N}=35)$ distributed as follows: professional nurse $(n=1)$, technical nurse $(n=19)$, assistant nurse $(n=3)$ and auxiliary workers (12) were included to monitor and calculate the time of their activities during the observed operations:

- The Head Nurse of operating theater (1 Nurse) is a nurse has baccalaureate degree in nursing, (17 Nurses) have secondary diploma nursing school, (2 Nurses) have Health Technical Nursing Institute, and (3 Assistant Nurses) have a diploma in Agriculture in additional training in indirect care in operating theater (12) have primary and preparatory schools certifications, all of the working auxiliaries, in the operating theater observed activities during operations to .monitor and calculate the time.

\section{Data Collection Tools}

Tool One: Retrospective Review Tool of operations Performed in Year (2011) adopted from by Salem (1998) aimed to:

- Determine the type and number of operations performed one year prior to the year of current study.

- Calculate the type and number of operations and classification.

This tool comprised of three columns for each operation (Major, Minor; and Technically Advanced operations) and twelve rows for twelve months of the year 2011. By reviewing the general operating theater computerized file depending on the hospital classification system for the operations, then the average number was calculated for each month, for each week, and each classification also.

Tool Two:_"Monitoring Form for Operating theater" adopted from Salem (1998) to record activities performed by nursing staff and auxiliary workers in order to:

- Identify the performed daily activities (pre, intraand post) operative by nursing personnel and auxiliaries attendant.

- Calculate consumed time for various activities carried out by the different staff working in the operating theater during each surgery.

Tool Three: "Costing and Pricing List Form for Surgical Procedures in Operating theater adopted from Salem (1998) aims to:

Estimate the basic price of direct and indirect medical supplies costs used for each surgery. 


\section{Operational design}

Preparatory phase

- This phase took about eight months from March 2012 to October 2012, reviewing the available literature concerning the study topic.

- Data were collected by the researcher from the defined study subjects by observing operations.

\section{A pilot study}

A pilot study was to estimate the time needed for filling the questionnaire. A pilot study was conducted for the duration of four weeks on general surgical operation theaters $(\mathrm{N}=20)$ distributed as major operations $(\mathrm{N}=7)$, minor operations $(\mathrm{N}=7)$ and technically advanced operations $(\mathrm{N}=6)$.The operations of the pilot study (20) were excluded because some items added on the cost pricing list form for a surgical procedure in operating theater.

When observed operations time for filling the used forms ranged from (30-90) minutes in minor operations up to (120-315) minutes in major operations, and from (60-135) minutes in technically advanced operations, where the nursing staff was observed for their activities from preparation for operation till the end of that operation; and their activities' consumed time were recorded directly after end each performed activity

\section{Field Work}

- The actual data collection extended from July 2012 until the end of December 2012, with total period of data collection (6) months. It was made by using a list of pricing according to the accounts Office of Operations in the General Department of Surgery at Assiut University Hospital (2011-2012).

- A retrospective review of operations computerized registered book for the year (2011); starting from January 2011 till the end of December 2011 was conducted in order to determine the type and number of operations performed one year prior to the year of the conduction of present study which carried out in (2012). The review yielded the following data:

- A total number of major operations (1328/year. 111/month.27/week).

- A total number of minor operations (1360/year. 113/month 28/week).

- A total number of technically Advanced operations (112 /year. 9/month. 3/week).

Calculation of cost by using Account Analysis Method

Estimates cost functions by classifying various cost accounts as variable and fixed costs with respect to the identified level of activity.

Estimate in the form of $\mathrm{Y}=\mathrm{f}+\mathrm{v}^{\mathrm{X}}$. That is Total mixed cost $=$ Total fixed cost $+($ Unit variable cost $\times$ Number of units).

Y: Total costs. f: fixed costs.

V: Unit variable cost.

$\mathrm{X}$ : number of cost units.

Administrative Design

- An Official approval to carry out the study was obtained from the persons Hospital director, Operating Theater director, and Head Nurses in operating theaters at Assiut University Hospital for permission to collect the necessary data for the present study.

- Written approval obtained from the Director of Assiut University Hospital, Director of Nursing, and Head of Operating Theaters

\section{Ethical considerations}

The oral agreement was taken from the study participants.

\section{Statistical design}

Data entry and statistical analysis were done using SPSS 16.0 statistical software package. Data for time and cost were presented using descriptive statistics in the form of frequencies and percentages for qualitative variables, means, standard deviations and medians for quantitative variables. Quantitative continuous data were compared using the nonparametric Kruskal-Wallis test for multiple group comparisons as a normal distribution of the data could not be assumed. Spearman rank correlation was used for assessment of the inter-relationships among quantitative variables and ranked ones. In order to identify the independent predictors of the total cost, multiple linear regression analysis was used after testing for normality, and homoscedasticity and analysis of variance for the full regression models were done. Statistical significance was considered at p-value $<0.05$. 


\section{Results}

Table (1): Personnel characteristics of the studied nurses in general surgical theater at Assuit University Hospital $(\mathbf{n}=\mathbf{2 0})$.

\begin{tabular}{|c|c|c|}
\hline Personnel Characteristics & Number & Percent \\
\hline \multicolumn{3}{|l|}{ Age in years } \\
\hline $20-$ & 4 & 20.0 \\
\hline $25-$ & 3 & 15.0 \\
\hline $35-$ & 8 & 40.0 \\
\hline $45-49$ & 5 & 25.0 \\
\hline \multicolumn{3}{|l|}{ Nursing qualification } \\
\hline Bachelor & 3 & 15.0 \\
\hline Technical institute diploma & 2 & 10.0 \\
\hline Nursing secondary schools diploma & 15 & 75.0 \\
\hline \multicolumn{3}{|l|}{ Experience years in nursing } \\
\hline$<5$ & 4 & 20.0 \\
\hline $5-$ & 8 & 40.0 \\
\hline $15+$ & 8 & 40.0 \\
\hline \multicolumn{3}{|l|}{ Experience years in operating theater } \\
\hline$<5$ & 6 & 30.0 \\
\hline $5-$ & 6 & 30.0 \\
\hline $15+$ & 8 & 40.0 \\
\hline
\end{tabular}

Table (2): Distribution of different types of operations and anesthesia used in general surgery operating theaters at Assuit University Hospital $(n=280)$.

\begin{tabular}{|l|c|c|}
\hline \multicolumn{2}{|c|}{ Frequency } & Percent \\
\hline Types of operations & 122 & 43.6 \\
\hline Minor & 106 & 37.9 \\
\hline Major & 52 & 18.6 \\
\hline Technically advanced & \multicolumn{2}{|c|}{} \\
\hline Anesthesia used & 197 & 70.4 \\
\hline General & 77 & 27.5 \\
\hline Spinal & 1 & 0.4 \\
\hline Local & 1 & 0.4 \\
\hline None & 4 & 1.4 \\
\hline General/spinal & & \\
\hline
\end{tabular}

Table (3): Comparison of materials' direct cost spent by types of operations.

\begin{tabular}{|c|c|c|c|c|c|}
\hline \multirow[b]{2}{*}{ Direct cost :( a) variable cost. } & \multicolumn{3}{|c|}{ Cost (LE) by type of operation } & \multirow{2}{*}{$\begin{array}{c}\text { Kruskal } \\
\text { Wallis } \\
\text { Test }\end{array}$} & \multirow[b]{2}{*}{ p-value } \\
\hline & Minor & Major & $\begin{array}{l}\text { Technically } \\
\text { advanced }\end{array}$ & & \\
\hline \multicolumn{6}{|l|}{ Anesthetics } \\
\hline Range & $0.0-85.0$ & $2.8-294.0$ & $0.0-189.4$ & & \\
\hline Mean \pm SD & $21.9 \pm 21.9$ & $70.5 \pm 40.3$ & $76.7 \pm 41.7$ & 124.64 & $<0.001^{*}$ \\
\hline Median & 9.00 & 68.3 & 72.6 & & \\
\hline \multicolumn{6}{|l|}{ Support medications } \\
\hline Range & $0.0-4.0$ & $0.0-82.0$ & $0.0-41.0$ & & \\
\hline Mean \pm SD & $0.3 \pm 0.9$ & $3.9 \pm 11.2$ & $2.2 \pm 6.4$ & 14.23 & $0.001 *$ \\
\hline Median & 0.00 & 0.00 & 0.00 & & \\
\hline
\end{tabular}




\begin{tabular}{|c|c|c|c|c|c|}
\hline \multirow[b]{2}{*}{ Direct cost :( a) variable cost. } & \multicolumn{3}{|c|}{ Cost (LE) by type of operation } & \multirow{2}{*}{$\begin{array}{c}\text { Kruskal } \\
\text { Wallis } \\
\text { Test }\end{array}$} & \multirow[b]{2}{*}{ p-value } \\
\hline & Minor & Major & $\begin{array}{l}\text { Technically } \\
\text { advanced }\end{array}$ & & \\
\hline \multicolumn{6}{|l|}{ Antibiotics } \\
\hline Range & $0.0-63.0$ & $0.0-46.0$ & $0.0-59.0$ & & \\
\hline Mean \pm SD & $17.2 \pm 12.8$ & $18.2 \pm 11.9$ & $17.1 \pm 15.0$ & 1.24 & 0.54 \\
\hline Median & 22.00 & 17.00 & 17.00 & & \\
\hline \multicolumn{6}{|l|}{ Total anesthetics } \\
\hline Range & $0.0-117.8$ & $2.8-310.0$ & $0.0-211.7$ & & \\
\hline Mean \pm SD & $39.4 \pm 27.1$ & $92.5 \pm 43.1$ & $96.1 \pm 44.9$ & 110.77 & $<0.001 *$ \\
\hline Median & 31.8 & 93.3 & 92.7 & & \\
\hline \multicolumn{6}{|l|}{ Fluids } \\
\hline Range & $0.0-15.2$ & $0.0-32.4$ & $3.6-16.0$ & & \\
\hline Mean \pm SD & $4.2 \pm 2.5$ & $9.3 \pm 4.7$ & $8.8 \pm 4.0$ & 105.36 & $<0.001 *$ \\
\hline Median & 3.60 & 9.20 & 9.40 & & \\
\hline \multicolumn{6}{|l|}{ Gases } \\
\hline Range & $0.0-288.3$ & $18.3-618.3$ & $18.3-398.3$ & & \\
\hline Mean \pm SD & $45.2 \pm 48.0$ & $102.1 \pm 86.0$ & $102.0 \pm 75.0$ & 73.99 & $<0.001 *$ \\
\hline Median & 18.30 & 88.30 & 90.65 & & \\
\hline \multicolumn{6}{|l|}{ Disposables } \\
\hline Range & $1.9-263.0$ & $34.3-564.8$ & $36.0-618.9$ & & \\
\hline Mean \pm SD & $46.4 \pm 25.0$ & $100.0 \pm 72.5$ & $93.1 \pm 94.4$ & 134.02 & $<0.001 *$ \\
\hline Median & 42.5 & 79.5 & 65.4 & & \\
\hline \multicolumn{6}{|l|}{ Sutures } \\
\hline Range & $0.0-240.7$ & $0.0-486.2$ & $12.3-285.7$ & & \\
\hline Mean \pm SD & $46.3 \pm 39.9$ & $127.7 \pm 102.6$ & $122.4 \pm 72.3$ & 78.21 & $<0.001 *$ \\
\hline Median & 37.2 & 93.8 & 120.3 & & \\
\hline \multicolumn{6}{|l|}{ (b) fixed cost. Equipment } \\
\hline Range & $1.0-6.0$ & $0.0-7.0$ & $5.0-8.0$ & & \\
\hline Mean \pm SD & $4.1 \pm 1.6$ & $5.6 \pm 1.1$ & $6.3 \pm 0.7$ & 95.33 & $<0.001 *$ \\
\hline Median & 4.00 & 6.00 & 6.00 & & \\
\hline \multicolumn{6}{|l|}{ Steriles } \\
\hline Range & $1.2-20.7$ & $0.0-21.7$ & $9.2-21.7$ & & \\
\hline Mean \pm SD & $19.8 \pm 3.4$ & $20.1 \pm 3.2$ & $15.6 \pm 5.1$ & 43.65 & $<0.001^{*}$ \\
\hline Median & 20.7 & 20.7 & 12.4 & & \\
\hline \multicolumn{6}{|l|}{ Total fixed } \\
\hline Range & $3.2-26.7$ & $0.0-27.7$ & $14.2-29.7$ & & \\
\hline Mean \pm SD & $23.9 \pm 4.0$ & $25.7 \pm 4.0$ & $21.8 \pm 4.8$ & 53.87 & $<0.001 *$ \\
\hline Median & 24.70 & 26.70 & 19.35 & & \\
\hline \multicolumn{6}{|l|}{ Total materials( Direct cost ) } \\
\hline Range & $41.6-485.2$ & $202.6-1131.2$ & $180.3-1079.7$ & & \\
\hline Mean \pm SD & $205.2 \pm 90.6$ & $457.1 \pm 198.1$ & $444.1 \pm 182.2$ & 67.84 & $<0.001 *$ \\
\hline Median & 192.7 & 399.5 & 411.5 & & \\
\hline
\end{tabular}

(*) Statistically significant at $p<0.05$

N.B. The cost in Egyptian pound (L.E). 
Table (4): Comparison of total costs spent (indirect costs) by operating team with types of operations at Assuit University Hospital.

\begin{tabular}{|c|c|c|c|c|c|}
\hline \multirow[b]{2}{*}{$\begin{array}{l}\text { Variables of indirect } \\
\text { costs }\end{array}$} & \multicolumn{3}{|c|}{ Cost (LE) by type of operation } & \multirow{2}{*}{$\begin{array}{c}\text { Kruskal } \\
\text { Wallis } \\
\text { Test }\end{array}$} & \multirow[b]{2}{*}{ p-value } \\
\hline & Minor & Major & $\begin{array}{l}\text { Technically } \\
\text { advanced }\end{array}$ & & \\
\hline \multicolumn{6}{|l|}{ Nursing } \\
\hline Range & $2.2-147.4$ & $25.9-661.2$ & $24.7-444.1$ & & \\
\hline Mean \pm SD & $42.6 \pm 29.6$ & $116.4 \pm 94.0$ & $124.8 \pm 90.1$ & 1.40 & $<0.001^{*}$ \\
\hline Median & 38.95 & 86.7 & 88.7 & & \\
\hline \multicolumn{6}{|l|}{ Surgeons } \\
\hline Range & $188.0-188.0$ & $336.0-336.0$ & $706.0-706.0$ & & \\
\hline Mean \pm SD & $188.0 \pm 0.0$ & $336.0 \pm 0.0$ & $706.0 \pm 0.0$ & 279.00 & $<0.001^{*}$ \\
\hline Median & 188.00 & 336.00 & 706.00 & & \\
\hline \multicolumn{6}{|l|}{ Anesthsia } \\
\hline Range & $41.0-41.0$ & $88.0-88.0$ & $175.0-175.0$ & & \\
\hline Mean \pm SD & $41.0 \pm 0.0$ & $88.0 \pm 0.0$ & $175.0 \pm 0.0$ & 279.00 & $<0.001^{*}$ \\
\hline Median & 41.00 & 88.00 & 175.00 & & \\
\hline \multicolumn{6}{|l|}{ Operating theater } \\
\hline Range & $34.0-34.0$ & $74.0-74.0$ & $108.0-108.0$ & & \\
\hline Mean \pm SD & $34.0 \pm 0.0$ & $74.0 \pm 0.0$ & $108.0 \pm 0.0$ & 279.00 & $<0.001^{*}$ \\
\hline Median & 34.00 & 74.00 & 108.00 & & \\
\hline \multicolumn{6}{|l|}{ Total costs } \\
\hline Range & $318.7-873.4$ & $746.4-2136.9$ & $1203.1-2162.5$ & & \\
\hline Mean \pm SD & $510.8 \pm 106.2$ & $1071.5 \pm 259.5$ & $1557.9 \pm 234.8$ & 85.75 & $<0.001^{*}$ \\
\hline Median & 502.8 & 984.3 & 1514.3 & & \\
\hline
\end{tabular}

(*) Statistically significant at $p<0.05$

Table (5): Relation between total nursing costs and nurses' personnel characteristics at Assuit University Hospital.

\begin{tabular}{|c|c|c|c|c|}
\hline \multirow{2}{*}{ Personnel Characteristics } & \multicolumn{2}{|c|}{ Total nursing cost (LE) } & \multirow{2}{*}{$\begin{array}{c}\text { Kruskal } \\
\text { Wallis } \\
\text { Test } \\
\end{array}$} & \multirow{2}{*}{ p-value } \\
\hline & Mean \pm SD & Median & & \\
\hline \multicolumn{5}{|l|}{ Age in years } \\
\hline $20-$ & $40.5 \pm 46.5$ & 29.8 & & \\
\hline $25-$ & $76.3 \pm 79.8$ & 52.0 & 83.92 & $<0.001^{*}$ \\
\hline $35-$ & $76.3 \pm 47.8$ & 68.0 & & \\
\hline $45-49$ & $146.9 \pm 113.6$ & 121.8 & & \\
\hline \multicolumn{5}{|l|}{ Nursing qualification } \\
\hline Bachelor & $27.9 \pm 14.9$ & 28.1 & & \\
\hline Technical institute diploma & $24.1 \pm 22.5$ & 15.0 & 77.96 & $<0.001^{*}$ \\
\hline Nursing secondary schools diploma & $95.7 \pm 83.7$ & 70.7 & & \\
\hline \multicolumn{5}{|l|}{ Experience years in nursing } \\
\hline$<5$ & $26.6 \pm 15.8$ & 25.9 & & \\
\hline $5-$ & $77.3 \pm 59.3$ & 65.7 & 10.06 & $<0.001^{*}$ \\
\hline $15+$ & $117.4 \pm 98.2$ & 87.4 & & \\
\hline \multicolumn{5}{|l|}{ Experience years in operating theater } \\
\hline$<5$ & $58.5 \pm 34.6$ & 51.2 & & \\
\hline $5-$ & $81.0 \pm 66.8$ & 68.0 & 19.68 & $<0.001^{*}$ \\
\hline $15+$ & $118.3 \pm 98.5$ & 87.4 & & \\
\hline
\end{tabular}

(*) Statistically significant at $p<0.05$

N.B. The cost in Egyptian pounds (L.E). 
Table (6): Relation between total operations costs (direct \& indirect costs) and nurses' personnel characteristics at Assuit University Hospital.

\begin{tabular}{|c|c|c|c|c|}
\hline \multirow{2}{*}{ Personnel Characteristics } & \multicolumn{2}{|c|}{ Total cost (LE) } & \multirow{2}{*}{$\begin{array}{c}\text { Kruskal } \\
\text { Wallis } \\
\text { Test }\end{array}$} & \multirow[b]{2}{*}{ p-value } \\
\hline & Mean \pm SD & Median & & \\
\hline \multicolumn{5}{|l|}{ Age in years } \\
\hline $20-$ & $706.8 \pm 359.3$ & 564.4 & & \\
\hline $25-$ & $1003.3 \pm 426.9$ & 978.6 & 5.76 & 0.12 \\
\hline $35-$ & $964.1 \pm 434.7$ & 919.8 & & \\
\hline $45-49$ & $960.4 \pm 493.0$ & 877.3 & & \\
\hline \multicolumn{5}{|l|}{ Nursing qualification } \\
\hline Bachelor & $710.2 \pm 321.7$ & 610.8 & & \\
\hline Technical institute diploma & $593.7 \pm 329.3$ & 459.3 & 5.72 & 0.06 \\
\hline Nursing secondary schools diploma & $960.3 \pm 448.4$ & 920.9 & & \\
\hline \multicolumn{5}{|l|}{ Experience years in nursing } \\
\hline$<5$ & $707.2 \pm 342.3$ & 554.7 & & \\
\hline $5-$ & $955.7 \pm 420.7$ & 915.9 & 7.47 & $0.02 *$ \\
\hline $15+$ & $968.0 \pm 480.6$ & 912.5 & & \\
\hline \multicolumn{5}{|l|}{ Experience years in operating theater } \\
\hline$<5$ & $946.3 \pm 432.3$ & 876.00 & & \\
\hline $5-$ & $905.5 \pm 408.7$ & 898.1 & 0.40 & 0.82 \\
\hline $15+$ & $973.9 \pm 481.7$ & 913.6 & & \\
\hline
\end{tabular}

(*) Statistically significant at $p<0.05$

N.B. The cost in Egyptian pounds (L.E).

Table (7): Correlation between operations' time, cost, and nurses' personnel characteristics at Assuit University Hospital.

\begin{tabular}{|l|c|c|c|c|}
\hline \multirow{2}{*}{} & \multicolumn{4}{|c|}{ Spearman's rank correlation coefficient } \\
\cline { 2 - 5 } & Age & Qualification & $\begin{array}{c}\text { Experience } \\
\text { (nursing) }\end{array}$ & $\begin{array}{c}\text { Experience } \\
\text { (OT) }\end{array}$ \\
\hline Total nursing time & -0.01 & 0.10 & -0.03 & -0.01 \\
\hline Total operation time & -0.01 & 0.11 & -0.03 & -0.01 \\
\hline Cost of supplies & 0.04 & $0.18^{* *}$ & 0.06 & 0.06 \\
\hline Total nursing costs & $0.524^{* *}$ & $0.47^{* *}$ & $0.54^{* *}$ & $0.48^{* *}$ \\
\hline Total operations cost & $0.16^{* *}$ & $0.26^{* *}$ & $0.16^{* *}$ & 0.10 \\
\hline
\end{tabular}

(**) Statistically significant at $p<0.01$

Table (8): Best fitting multiple linear regression models for total operation costs at Main Assuit University Hospital (2012).

\begin{tabular}{|l|c|c|c|c|c|c|c|}
\hline \multirow{2}{*}{} & \multicolumn{2}{|c|}{$\begin{array}{c}\text { Unstandardized } \\
\text { Coefficients }\end{array}$} & \multirow{2}{*}{$\begin{array}{c}\text { Standardized } \\
\text { Coefficients }\end{array}$} & \multirow{2}{*}{ t-test } & \multirow{2}{*}{ p-value } & \multicolumn{2}{|c|}{$\begin{array}{c}\text { 95\% Confidence } \\
\text { Interval for B }\end{array}$} \\
\cline { 2 - 5 } & B & Std. Error & & & & Lower & Upper \\
\hline Constant & -106.4 & 39.7 & & -2.68 & 0.008 & -184.6 & -28.2 \\
\hline Experience in OT & 25.5 & 6.9 & 0.10 & 3.71 & $<0.001$ & 11.9 & 38.9 \\
\hline $\begin{array}{l}\text { Type of operation } \\
\text { (reference: minor) }\end{array}$ & 529.2 & 15.8 & 0.89 & 33.53 & $<0.001$ & 498.2 & 560.3 \\
\hline
\end{tabular}

$R$-square $=0.81 \quad$ Dependent variables: Total operations costs $\quad$ Model ANOVA: $F=570.50, p<0.001$

Variables entered and excluded: age, qualification, job position, total experience 
Table (1): Shows that $40 \%$ of the studied nurses aged from 35 to less than 45 years had more than 15 years of experience in operating theater and in nursing. Three-quarters of the studied nurses had nursing secondary school while, less than one-quarter of the studied nurses aged less than 25 years, As regards educational level had technical Institute with less than 5 years' experience in operating theater and in nursing.

Table (2): Illustrated that less than half of operations $(43.6 \%)$ were minor, while only $(18.6 \%)$ were technically advanced operations. Regarding anesthesia used $70.4 \%$ were general anesthesia, and only $(0.4 \%)$ were local anesthesia.

Table (3): Shows that the variable costs, the total anesthetics represent the highest cost among the direct costs for technically advanced operations (96.1 \pm 44.9), as regard to variable costs the disposables represent the highest cost among the direct costs for major operations $(100.0 \pm 72.5)$. as regard to variable costs, sutures represent the highest cost among the direct costs for major operations (127.7 \pm 102.6 ), Moreover total fixed costs represent the highest cost among the direct costs for major operations $(25.7 \pm 4.0)$ In addition, the table shows that the total materials for variable costs \&fixed costs represent the highest cost among the major operations (457.1 \pm 198.1). Also, the table shows that the differences between the means of all costs related items were highly statistically significant differences at $(p<0.001 *)$ level in relation to the operational classifications.

Table (4): Shows that the surgeons \&anesthesia represents the highest costs among the indirect costs for technically advanced operations (706.0 \pm 0.0 ) (175.0 \pm 0.0$)$ In addition, the table shows that nursing \&operating theater represents the highest costs among the (indirect costs) for technically advanced operations (124.8 \pm 90.1) (108.0 \pm 0.0$)$ respectively. Also, it reveals that the total cost represents the highest costs among indirect costs for technically advanced operations (1557.9 \pm 234.8). Moreover, there were a highly differences between the means of all costs related items with statistically significant differences at $(\mathrm{p}<0.001 *)$ level in relation to the operational classifications.

Table (5): Shows that highest mean scores among nursing secondary school, who aged from 45 to 49 years, had more than 15 years of experiences in nursing and in operating theater. In addition, there were statistical significance differences between total nursing costs \& nurses' personnel characteristics $(\mathrm{P}<$ $0.001 *)$.

Table (6): Shows that highest mean scores among nursing secondary school, who aged from 25 to less than 35 years, had more than 15 years, of experiences in nursing and in operating theater. In addition, there was a statistical significance Relation between total operations costs (direct $\&$ indirect costs) \& years of experience in nursing $(\mathrm{p}<0.02 *)$.

Table (7): Shows that there were strong positive correlations among age, qualification, and experience in nursing and in operating theater with total nursing costs. $\quad(\mathrm{r}=524 * * ; \quad 0.47 * * ; \quad 0.54 * * ; \quad$ and $0.48 * *)$ respectively, also, positive correlations among age, qualification, and experience in nursing with total operations cost $\left(\mathrm{r}=16^{* *} ; \quad \mathrm{r}=26^{* *} ; \quad \mathrm{r}=16^{* *}\right)$ respectively, with a highly statistically significant Relations $\left(\mathrm{p}<0.01^{* *}\right)$. In addition, there were a negative correlation among age, experience in nursing and in operating theater with total nursing time $(\mathrm{r}=-0.01 ; \mathrm{r}=-0.03 ; \mathrm{r}=-0.01)$ respectively; also, a negative correlation among age, experience in nursing and in operating theater with total operation time $(r=-0.01 ; r=-0.03 ; r=-0.01)$ respectively.

Table (8): Illustrates that the best fitting multiple linear regression models for total operations cost scores, as a dependent factor, \& the scores of staff nurse's personnel characteristics, as independent factors. The model indicates that the only significant predictor of total operations costs experienced in operating theater, the other factors being excluded for lack of statistical significance. From the model, beta coefficient $=-106.4$, experience in operations is negatively associated with total operations costs. i.e. as the staff nurse's experience in operating theater increases, his/her total operations costs score decreases. According to the $r=0.81$, experience in operations, type of operation statistically significant predictor of total operational costs standardized coefficients $=0.10,(\mathrm{p}<0.001)$.

\section{Discussion}

Hospitals face particular demands to provide quality care while curbing costs by eliminating wasted materials, effort, and time. With renewed vigor and focus, stakeholders are calling on hospitals to improve efficiency in expensive areas like the operating theater. Key to the success of smooth functioning of the operating theater (OT) is the nursing staff that coordinates patient flow and anticipates surgical technique (Emanuel, 2012).

Operating theater cost constitutes a huge investment of healthcare resources, approximating one-third of total hospital budget. Thus, there is an increasing interest in providing an "efficient" anesthetic and surgical service, to make operations the largest potential source of income (Stavrou et al., 2014).

The results of the present study as shown in declared that there was less than half of types of operations had minor operations and $70.4 \%$ receiving general 
anesthesia. Also, results of the study showed that the technically advanced operations done under the general anesthesia were the highest in variable costs, fixed costs, and indirect costs. This may be due to the costs of using anesthetic gases, and use of the expensive anesthetic drugs (e. g, induction agent, neuromuscular blocking drugs, and volume expanders) in addition to the high price of equipment's that used for a long period to monitor and ventilate the patients during surgeries under general anesthesia which caused the high fixed costs of surgeries. Meanwhile, the costs of spinal anesthesia during minor or major operations in the study results were less in their direct variable cost, fixed costs and indirect costs. This finding was consistent with Salem, (1998) who found in his results that the minor, major surgeries done under the general anesthesia were the highest basic average price direct variable costs. While the minor, major surgeries under spinal anesthesia were less in their direct variable cost due to their lower consuming of the medication, disposable supplies, so they were less in their total expenses comparing with the minor and major surgeries done under general anesthesia. Also, Schuster et al., (2005) in a retrospective chart analysis on patients undergoing various surgical procedures and anesthetic drug regimes found that spinal anesthesia offers a cost advantage over general anesthesia. They also underlined that cost comparisons of anesthesia techniques largely depend on the surgical duration of the cases studied. Any estimates provided are not exact because we cannot know in advance the type and amount of care you and your provider will decide is needed. Your charges will depend on the actual services you receive. The international cost of minor operation as Tonsillectomy surgery costs ranged from $\$ 3300$ to $\$$ 7800 Major operation as Breast implant Cost Range: $\$ 5,000-\$ 10,000$ while technically advanced operations as Laparoscopy, Cholecystectomy (Gallbladder Removal) Average Total Cost ranged from $\$ 2,700$ - $\$ 7,300$

(http:///www.newchoicehealth.com, 2016).

The results of the present study as shown in revealed that there was statistically significant relation between the costs means of major and technically advanced operations. Also, that the direct (variable, fixed) and indirect costs were higher for major and technically advanced operations than minor operations. This may be due to high expensive disposable medical supplies such as a laparoscope, blades, forceps, homeostasis (to clamp bleeding vessels), retractors, scissors and instruments that cause much more need for maintenance, sterilization, and consumption which in turn increase the technically advanced operations costs. The use of major and technically advanced operations such as laparoscopy, surgical microscope and other high technology equipment's, leads also to increase the costs of major and technically advanced operations while less half of the minor operations were consuming less new technological instruments, disposable medical supplies, and equipment. This finding is consistent with findings of the study conducted by Salem, (1998) who calculated the total average basic price in Egyptian Pounds of the operating room in order to develop a model for basic pricing in the operating room at the Nile Badrawy Hospital. She stressed that the minor operations used less disposable medical supplies, equipment and instrument, anesthesia medications, and shorter duration of the operations were less in their expenses comparing with the major operations.

In the same line Colak, (2004) found that the use of disposable instruments in technically advanced operations is part of modern medicine. Ideally, the reuse of disposable laparoscopic instruments (DLI) should not be allowed, but the provision of medical services requires that considerable thought is given to the subject of costs, and one of the major reasons driving the reuse of (DLI) is cost containment. The reuse of single-use medical devices is, therefore, a common practice in many countries.

Concerning with indirect cost results shown that the indirect costs for all surgeries, anesthesia, nursing and operating theater represent the highest costs among the indirect costs for technically advanced operations than in major and minor operations. This may be attributed to the fact that the indirect costs were depending on the surgery's duration whereas the costs of water, electricity and the salary of staff in operating theater are increased as the working time is increased. Moreover, this finding supported by Daoud, (2010) who found that indirect costs increased when working time is increased. In addition, McLaughlin, (2012) found that cost is considered as a combination of two elements which are money and time thus the spending times in various operations are another dimensions bearing on the overall cost of surgical procedures in the operating theater. Surgery scheduling lies at the heart of any operating theater, it works to determine staff productivity and operating theater use and affects nurses, physicians, patients, families, employees, and other facilities.

Ongoing the study finding revealed that there was statically significant relation for all items included in the table. This finding was inconsistent with Daoud, (2010) who found that there was no statistical significance relation between total nursing costs \& nurses' personal characteristics. 
From another perspective, the finding of the present study as shown revealed that there was a statistically significant relation between total operations costs (direct \& indirect costs) \& years of experience in nursing. That is because nurses with more age and years of experience become less participative in direct nursing care in operating theater.

The findings of the present study as shown in clarified that there were strong positive correlations among age, qualification, and experience in nursing and in operating theater with total nursing costs. This clarifies that when nurse's age, qualification, and experience in nursing and in operating theater increased to become more experience, skillful, and able to do assist for any operation results increased total nursing costs. This result supported by McLaughlin, (2012) who found that an aging nursing workforce, and changes in accessibility to health care through the Affordable Care Act ( ACA) signal that nursing leaders must make wise choices about staffing assignments, training, and structure. The theme of "working smarter" suggests that managers may maximize efficiency by realigning nursing staff arrangements rather than hiring more workers or promoting longer workdays.

Also, the table shows a positive correlation among age, qualification, and experience in nursing and total operations cost. The same table clarified that there was a negative correlation between age, experience in nursing and in operating theater with total nursing time and total operation time. This finding was in accordance with the finding of Ballantyne et al., (2010) who concluded that experience of the surgical team members, familiarity with available infrastructure aids in reducing operative times.

From another perspective, the results of the present study as shown in declared that there was a negative statistically significant correlation between the scores of experience in operating theater and total operations costs. This may be due to that when nurses become more experience and skillful, inspire others with the vision of what can be accomplished, leads to assist the surgeon rapidly results in deceased operations costs. In the same line, Schneider et al., (2011) studied the effects of the surgeon, patient, and environmental characteristics on predictions of perioperative time. Highly experienced surgeons, having completed more than 1,000 procedures, had a strong influence on operative time, whereas less experience was associated with longer surgical durations. The authors acknowledged that the experience of others on the surgical team may affect surgical time.

Also, McLaughlin, (2012) reported that there was specialty surgical teams experienced in particular techniques such as laparoscopy may contribute to OT efficiency by reducing operative times and complications. Moreover, Cassera et al., (2009) analyzed 360 general laparoscopic cases and found a relationship between procedure times and a number of nurses taking part in the procedure; holding constant procedure complexity and patient status, an additional team member predicted a procedure time increase of more than 15 minutes. Also, Australian Bureau of Statistics [ABS] 2008, \& World Health Organization [WHO], 2006) supported this finding and concluded that nurses comprise the majority of healthcare professionals in acute care facilities, providing safe and appropriate healthcare relies on a sustainable and competent workforce to deliver optimal patient outcomes .

\section{Conclusions}

\section{In the light of the study results, the following} conclusions can be drawn:

- The cost of surgery was directly linked to the utilization of the operation theater time, duration of anesthesia, quantities of disposable medical supplies, the total time of using equipments and surgical instruments in general.

- The basic direct (variable - fixed) cost and indirect costs were higher for technically advanced operations and major operations than minor operations.

- All the minor operations used less disposable medical supplies, equipment and instrumentation, anesthesia medications, and shorter duration of the operation and were less in their all expenses.

- Major operations and technically advanced operations done under general anesthesia were the highest mean scores in their basic direct variable, basic direct fixed and indirect costs means.

- The minor, major operations done under spinal anesthesia were less in their direct variable cost.

- An indirect cost for all surgeries, anesthesia, nursing and operating theaters represents the highest costs among the (indirect costs) for technically advanced operations than in major and minor operations.

- Longest time spent in minutes by anesthesia, circulatory, scrub nurses and total nursing in major and technically advanced operations .All observed nursing staff categories also spend a longer time in operations done under general anesthesia than that time in spinal anesthesia.

- Strong positive correlations among age, qualification, and experience in nursing and in operating theater with total nursing costs.

- Negative correlation among age, experience in nursing and in operating theater with total nursing time and total operation time. 


\section{Recommendations}

Based on the foregoing conclusions, the following recommendations are proposed

- Increase awareness of nurses about the importance of calculating the cost to maintain cost reduction.

- Proper utilization of operating theater time by using an organized surgeries list and coordinating activities between the surgical departments and operating theater to reduce the surgery's waiting time.

- In-service training programs for newly employed nursing personnel about operating theater services.

\section{References}

1. Australian Bureau of Statistics, (2008): Selected Health Occupations: Australia; 2006. Australian Bureau of Statistics, Canberra. Available at http://www.abs.gov.au/ausstats/abs@.nsf/mf/481 9.0 (accessed 29.01. 12).

2. Ballantyne G., Ewing D., Capella R., Capella J., Davis D., Schmidt H., Wasielewski, A., \& Davies R., (2010): The learning curve measured by operating times for laparoscopic and open gastric bypass: Roles of surgeon's experience, institutional experience, body mass index and fellowship training [Electronic version]. Obesity Surgery, 15(2): P.p 172-182.

3. Bank of Valletta Review, (2007): Estimating the shadow price of surgical procedures in the Maltese public health sector. Bank of Valletta Review, spring ;( 35): P.p.55-75.

4. Cassera, M.., Zheng, B., Martinec, D., Dunst, C., \& Swanstrom, L., (2009): Surgical Time independently affected by surgical team size. The American Journal of Surgery, 198(2) P.p : 216-222.

5. Colak, T., (2004): Efficacy and safety of reuse of disposable laparoscopic instruments in laparoscopic cholecystomy. A prospective randomized study. Surgical Endoscopy 2004: 18(5): P.p 727- 731

6. Dall T., Chen Y., Seifert R., (2009): The Economic value of professional nursing. Medical Care; 47(1): P.p97-104.

7. Daoud B., (2010): Estimating cost of operating theater of nursing services. Unpublished doctorate dissertation: Nursing Faculty, Alexandria University.

8. Dexter F., Willemsen Dunlap A., Lee J., (2007): Operating Room Managerial DecisionMaking on the Day of Surgery with and Without Computer Recommendations and Status Displays. Anesth Analg(105): P.p. 419-29.
9. Diers D., Bozzo J., (1997): Nursing resources definition in DRGs. Nursing Economics; 15(3): P.p.124-34.

10. Emanuel, E., (2012): In medicine, falling for fake innovation. New York Times. Retrieved June 27, 2012, from http://opinionator.blogs.nytimes.com/2012/05/27 /inmedicinefalling-for-fake-innovation.

11. Kaiser F., (2009): Employer health benefits annual survey. September 2009.

12. Klainberg M., Dirschel K., (2010): Today's Nursing Leader. Managing, Succeeding, Excelling; P.P 181.

13. Lemke H., Ratib O., Hori S., (2005): Workflow in the operating room: A summary review of the arrowhead 2004 seminar on imaging and informatics. International Congress Series 2005; 1281: P.p 862-67. Available online from: www.ics-elsevier. Com.

14. McLaughlin M., (2012): A model to evaluate efficiency in operating room processes. University of Michigan, 2012.

15. Salem N., (1998): Developing model for basic pricing in the operating theater. Unpublished doctorate dissertation: Alexandria University, Nursing Faculty.

16. Schneider A., Wilhelm D., Schneider M., Schuster T., Kriner M., and Leuxner, C., (2011): Laparoscopic cholecystectomy astandardized routine laparoscopic procedure: Is it possible to predict the duration of an operation? Journal of Health Care Engineering, 2(2): P.p 259-270.

17. Schuster M., Gottschalk A., \& Berger J., Standi T., (2005): Aretrospective comparison of costs for regional and general anesthesia techniques, Anesthesia \&Analgesia 2005: 100(3): 786-794.

18. Stavrou G., Panidis S., Tsouskas J., (2014): An Audit of Operating Room Time Utilization in a Teaching Hospital: Is There a Place for Improvement? ISRN Surgery, Volume 2014 Article ID 431740, 6 pageshttp://dx.doi.org/10.1155/2014/431740.

19. World Health Organization. (2006): Draft outline: World Report 2006. World Health Organization, Geneva. Available at: www.who/int/hrh/whr06_consultation/en/index.h tml (accessed 17.1.12).

20. http://www.newchoicehealth.com/laparoscopy -cholecystectomy, (2016). 